\title{
Mouse macrophage innate immune response to chikungunya virus infection
}

\author{
Shiril Kumar ${ }^{1}$, Marie-Christine Jaffar-Bandjee ${ }^{1,2}$, Claude Giry ${ }^{1}$, Léa Connen de Kerillis ${ }^{1}$, Andres Merits ${ }^{3}$, \\ Philippe Gasque ${ }^{1}$ and Jean-Jacques Hoarau ${ }^{1,4^{*}}$
}

\begin{abstract}
Background: Infection with Chikungunya alphavirus (CHIKV) can cause severe arthralgia and chronic arthritis in humans with persistence of the virus in perivascular macrophages of the synovial membrane by mechanisms largely ill-characterized.

Findings: We herein analysed the innate immune response (cytokine and programmed cell death) of RAW264.7 mouse macrophages following CHIKV infection. We found that the infection was restrained to a small percentage of cells and was not associated with a robust type I IFN innate immune response (IFN-a4 and ISG56). TNF-a, IL-6 and GM-CSF expression were upregulated while IFN- $\gamma, \mathrm{IL}-1 \mathrm{a}, \mathrm{IL}-2, \mathrm{IL}-4, \mathrm{IL}-5, \mathrm{IL}-10$ or IL-17 expression could not be evidenced prior to and after CHIKV exposure. Although CHIKV is known to drive apoptosis in many cell types, we found no canonical signs of programmed cell death (cleaved caspase-3, -9) in infected RAW264.7 cells.

Conclusion: These data argue for the capacity of CHIKV to infect and drive a specific innate immune response in RAW264.7 macrophage cell which seems to be polarized to assist viral persistence through the control of apoptosis and IFN signalling.
\end{abstract}

Keywords: Chikungunya virus, Macrophage, Apoptosis, Viral persistence, Inflammation

\section{Introduction}

Chikungunya virus (CHIKV) belongs to genus Alphavirus of the Togaviridae family and was first isolated in Tanzania in 1953 [1,2]. The viral genome is a single strand positive sense RNA of approximately $12 \mathrm{~kb}$. Together with other alphaviruses such as Ross river virus (RRV), Semliki forest virus and Sindbis virus (SINV), they are significant causes of arthritis in elderly patients [3-6].

The innate immune response can be engaged by several virus-associated molecular patterns recognized by a plethora of pattern recognition receptors (PRRs) such as toll-like receptors (TLRs), retinoic acid inducible gene-I (RIG-I) like receptors (RLRs), nucleotide oligomerization domain like receptors and protein kinase receptor $[7,8]$. These receptors, upon activation, switch on several

\footnotetext{
* Correspondence: Jean-Jacques.Hoarau@univ-reunion.fr

${ }^{1}$ GRI/IRG (EA4517), Immunopathology and infectious diseases research grouping, University of La Reunion, CHU and CYROI research centres, St-Denis, La Reunion, France

${ }^{4}$ GRI - (EA4517) Université de la Réunion, Recherche - RDC, CHU Félix-Guyon, Bellepierre, Saint-Denis cedex, lle de la Réunion 97405, France (DOM)

Full list of author information is available at the end of the article
}

genes which may regulate a protective response through the production of interferon (IFN) and IFN-stimulated genes (ISG).

Apoptosis or programmed cell death is one of the mechanisms used to limit viral dissemination to other cells [9]. Caspases are the main executor of apoptosis. Depending on their role, they are categorized into initiators (caspase-2,-8,-9-10), effectors or executioners (caspase-3,$6,-7)$ and inflammatory caspases (caspase-1,-4, -5) $[10,11]$.

Recent human and non-human primate studies have shown that CHIKV can infect monocytes/macrophages and can also persist in perivascular macrophages of the synovial tissue in chronic conditions [12-15]. Interestingly, only a subset of human monocyte/macrophage cells (less than $10 \%$ of the CD14+ cells) can be infected in vitro and leading to a rather transient innate immune response (IL-8, RANTES, IFN- $\alpha$ ) which rapidly tails off at $48 \mathrm{~h}$ post-infection (PI). Further FACS analyses of the infected monocyte cultures showed that expression of activation markers such HLA-DR and adhesion molecules CD54 (ICAM-1), CD106 (VCAM-1), and CD31 (PECAM-1) were not modified after CHIKV infection

\section{Biomed Central}


[14]. In contrast, a decrease in CD14 expression on CHIKV-infected blood monocytes may be associated with apoptosis by unknown mechanisms [14].

Here we used RAW264.7 mouse cell line to investigate the capacity of a CHIKV clinical isolate to infect mouse macrophages. We analysed the IFN $\alpha 4 /$ ISG56, the apoptosis and the cytokine responses prior to and after CHIKV infection. The relative contribution of these different pathways may help to decipher the plausible role of persistently CHIKV-infected macrophages in chronic arthritis as reported in human, monkey and more recently in mice [16].

\section{Materials and methods CHIKV isolate}

CHIKV (clone \#4), isolated from a patient's serum during the 2006 epidemic at Reunion island, was collected as part of the research program supported by a PHRC (health French Ministry). The research protocol was validated by the Tours IRB France (Agreement 2006-10) and collection was consented for by the patient. After amplification by a single passage on Vero cells, supernatant was collected when cytopathic conditions were detected, centrifuged at $2000 \mathrm{rpm}$ and $0.2 \mu \mathrm{m}$ filtered. Aliquots were stored at $-80^{\circ} \mathrm{C}$ until used. Serially diluted $\left(10^{-1}\right.$ to $\left.10^{-12}\right)$ virus were added to confluent Vero cell cultured in 96 well plate to establish the $\mathrm{TCID}_{50}$ estimated at $10^{7} / \mathrm{ml}$.

\section{Cells and culture condition}

Cell lines used were: mouse RAW264.7 macrophage (ECACC, 91062702), mouse CLTT astrocyte, African green monkey Vero cells (ATCC, CCL-81) and baby hamster kidney BHK-21 (ATCC, CCL-10). Cells were maintained in DMEM (PAN Biotech, France) medium, except BHK-21 in GMEM, containing 10\% heat inactivated FCS with penicillin $(100 \mathrm{U} / \mathrm{ml})$, streptomycin $(0.1 \mathrm{mg} / \mathrm{ml})$, sodium pyruvate $(100 \mathrm{mM})$, L-Glutamine $(200 \mathrm{mM})$ and fungizone $(0.5 \mu \mathrm{g} / \mathrm{ml})$ at $37^{\circ} \mathrm{C}$ under $5 \%$ $\mathrm{CO}_{2}$. For BHK-21, medium was supplemented with 10 $\mathrm{ml}$ HEPES (PAN Biotech) and $50 \mathrm{ml}$ of tryptose phosphate broth (Sigma). Infections were performed by addition of CHIKV at a multiplicity of infection of 1 .

\section{Quantitative RT-PCR (RT-qPCR)}

Total RNAs were extracted from culture cells using TRI$\mathrm{zol}^{\circledR}$ reagent (Invitrogen, France) and quantified using a picodrop (Labgene scientific, France). Reverse transcription (RT) was performed in a final volume of $30 \mu$ containing $3 \mu \mathrm{g}$ of RNA per reaction, $1 \mathrm{X}$ RT buffer, $5 \mu \mathrm{M}$ DTT, $1 \mathrm{Mm}$ dNTP mix, 7.5 U pDn6 and $60 \mathrm{U}$ RNasin incubated at $65^{\circ} \mathrm{C}$ for $5 \mathrm{~min}$ then cooled in ice for $5 \mathrm{~min}$ before addition of 98.4 $\mathrm{u}$ of Reverse transcriptase (MMLV) and again incubated at $37^{\circ} \mathrm{C}$ for $1 \mathrm{hr}$ followed by $5 \mathrm{~min}$ at $95^{\circ} \mathrm{C}$. All products were from Promega, France. RNA expression level between samples, for mouse interferon alpha-4 (IFNa4), mouse interferon stimulated gene-56 (ISG-56), tumor necrosis factor alpha (TNFa), were performed using SYBR RT-qPCR with the ABI7500 sequence detection system (Applied Biosystem, France). Mouse Glyceraldehyde-3phosphate dehydrogenase (GAPDH) was used as reference housekeeping gene. Cycling conditions were: $10 \mathrm{~min}$ at $95^{\circ}$ C followed by 40 cycles consisting on $15 \mathrm{sec}$ at $95^{\circ} \mathrm{C}, 30 \mathrm{sec}$ at $60^{\circ} \mathrm{C}$ and $45 \mathrm{sec}$ at $72^{\circ} \mathrm{C}$ before a final step to establish the dissociation curve. Amplicons were verified by $1.2 \%$ agarose gel-electrophoresis. CHIKV absolute quantification from infected cells and TCS was performed as previously described using a plasmid containing E1 insert as a standard, (kindly provided by Prof. X. de Lamballerie, Marseille, France) [12,17]. Primers used are listed in Table 1.

\section{Amplification of CHIKV positive or negative RNA strands}

Total RNAs from CHIKV infected cells (RAW264.7 or CLTT) or cell culture supernatant were extracted using the Nuclisens ${ }^{\circledR}$ easyMAG ${ }^{\circledR}$ system (bioMerieux SA, France). $2 \mu \mathrm{l}$ of $20 \mu \mathrm{M}$ biotinylated primers specific for either positive strand (CHIKV_Pos) or negative strand (CHIKV_Neg) of CHIKV E2 gene (CHIKV_E2 primers) were mixed with $2 \mu$ of total RNA for denaturation at $65^{\circ} \mathrm{C}$ for 2 minutes in a final volume of $20 \mu \mathrm{l}$, then cooled in ice for $5 \mathrm{~min}$. Reverse transcription (RT) was performed in a final volume of $20 \mu \mathrm{l}$ using the PrimeScript RT reagent kit (TAKARA, France), containing $4.5 \mu \mathrm{l}$ of denaturated RNA, $4 \mu \mathrm{l}$ of $5 \mathrm{X}$ RT buffer and $1 \mu \mathrm{l}$ of RT enzyme, in a thermocycler (Eppendorf, France) at $37^{\circ} \mathrm{C}$ for $15 \mathrm{~min}$ followed by $5 \mathrm{sec}$ at $85^{\circ} \mathrm{C}$. The biotinylated cDNAs were then purified using the Dynabeads M-270 streptavidin system (Invitrogen, France) and finally suspended in $20 \mu \mathrm{l}$ of EASY dilution solution (TAKARA, France). $5 \mu \mathrm{l}$ of purified cDNA were amplified in a final volume of $20 \mu \mathrm{l}$ containing $500 \mathrm{nM}$ of primers (CHIKV_ E2), $10 \mu \mathrm{l}$ of $2 \mathrm{X}$ SYBR Premix Ex Taq II polymerase buffer (TAKARA, France) with a LightCycler 480/96 (Roche, France). Cycling conditions were: $30 \mathrm{sec}$ at $95^{\circ} \mathrm{C}$ followed by 40 cycles consisting on $5 \mathrm{sec}$ at $95^{\circ} \mathrm{C}, 15 \mathrm{sec}$ at $56^{\circ} \mathrm{C}$ and $15 \mathrm{sec}$ at $72^{\circ} \mathrm{C}$ before a final step to establish the dissociation curve.

\section{Immunofluorescence staining (IFs)}

Adherent cells (RAW264.7 and CLTT cells) were grown on glass coverslips, washed to remove debris and fixed by chilled ethanol for $5 \mathrm{~min}$ at different time PI. Cells were incubated at $4^{\circ} \mathrm{C}$ overnight with primary antibody in PBS-BSA 1\%, washed 3 times in PBS followed by 2 hours incubation at room temperature with secondary antibody conjugated with Alexa Fluor 488 or 594 and DAPI (Invitrogen, France) in PBS/BSA. After washing in PBS, coverslips were mounted in Vectashield (VectorLab, 
Table 1 List of primers used

\begin{tabular}{llll}
\hline Gene & Primer $\mathbf{1}\left(\mathbf{5}^{\prime} \rightarrow \mathbf{3}^{\prime}\right)$ & Primer $\mathbf{2}\left(\mathbf{5}^{\prime} \boldsymbol{\rightarrow} \mathbf{3}^{\prime}\right)$ & Amplicon $\mathbf{( b p )}$ \\
\hline GAPDH & GAACGGGAAGTTGTCATCA & TGACCTTGCCCACAGCCTTG & 473 \\
IFNa4 & AGCCTGTGGATGCAGGAACC & CAGCAAGTGGTTGAGGAGAG & 171 \\
ISG56 & CTCAGAGCAGGTCCAGTTCC & TCCATCTCAGCACACTCCAG & 300 \\
TNFa & ACGGCATGGATCTCAAAGAC & CGGACTCCGCAAAGTCTAAG & 325 \\
CHIKV_E1 & AAGCTYCGCGTCCTTACCAAG & CCAAATTGTCCYGGTCTCCT & 209 \\
Probe_E1 & FAM - CCAATGTCYTCMGCCT & & \\
CHIKV_E2 & GGACACCTTT - TAMRA & ACGTGCTGCAAGGTARCTCT \\
CHIKV_Pos & ACKCTGACRGTGGGATTYAC & & 139 \\
CHIKV_Neg & ACGTGCTGCAAGGTARCTCT & & \\
\hline
\end{tabular}

France), visualized using a Nikon Eclipse 80i microscope with a Hamamatsu ORCA-ER camera and acquired with NIS-Element BR v2.30 imaging software (Nikon, France). Antibodies used were: Mouse monoclonal anti CHIKV E1 clone 6C4A5 (kindly provided by Biomerieux and IMTSSA, France), FDO (Human serum anti-CHIKV), rabbit anticleaved Caspase 9 (cell signaling, France), polyclonal rabbit anti-cleaved Caspase-3 (cell signaling), monoclonal rabbit anti p-IRF3 (cell signaling), polyclonal rabbit anti ISG-15 (cell signaling), rabbit anti-SFV Nsp1 (kindly provided by A. Merits) and mouse anti-dsRNA J2 (English and scientific consulting, Hungary). For each marker, photographs were taken with equal exposure time.

\section{Cytokines titration}

Cytokines released by RAW264.7 or CLTT cells in tissue culture supernatants (TCS) were measured using the mouse TNF $\alpha$ ELISA Ready-SET-GO kit (eBioscience, France) and by FACS using the mouse Th1/Th2 10 plex Flowcytomix kit (eBioscience, France) on a FC500 flow cytometer (Beckman coulter, France) according to manufacturer's protocols.

\section{Plaque assay}

Supernatant from cell cultures (TCS) infected by CHIKV were collected at 2, 8, 24 and $48 \mathrm{hrs}$ PI and filtered thru $0.2 \mu \mathrm{M}$. $300 \mu \mathrm{l}$ of diluted supernatant $\left(10^{-1}\right.$ to $10^{-7}$ dilution) in serum free GMEM medium was added on confluent BHK-21 cells grown on 6 well plates and incubated for 1 hour shaking every 10 minutes in an incubator at $37^{\circ} \mathrm{C}$ under $5 \% \mathrm{CO}_{2}$. After infectious media was aspirated, each well was overlaid with $2 \mathrm{ml}$ of $\mathrm{CMC} /$ GMEM mixture composed of 2 parts of $2 \%$ CMC (carboxymethylcellulose, Sigma) and 3 parts of complete GMEM containing 2\% FCS, then cultured for 72 hours. CMC/GMEM mixture was removed and cells were stained with crystal violet dye solution at room temperature for $30 \mathrm{~min}$. Plates were washed under tap water and the number of plaques/well were counted to determine the virus titter $(\mathrm{pfu} / \mathrm{ml})$ calculated as the number of plaques/well $\times$ Dilution factor $\times \mathrm{K}$ (compensation factor to $1 \mathrm{ml}$ ).

\section{TUNEL assay}

Infected cells were grown on coverslips for 8 and $24 \mathrm{hrs}$. To detect cells undergoing apoptosis, the Deadend colorimetric TUNEL system (Promega) was used according to the manufacturer's protocol. Coverslips were mounted with permanent mounting medium VectaMount (Vector laboratories, USA) for analysis.

\section{Statistical analysis}

Paired $t$ test statistical analysis was performed using Sigma plot version 9.0.1 software (Systat, UK). Values are represented as Mean \pm SEM from three independent experiments.

\section{Results}

CHIKV infects and replicates in a subset of RAW264.7 macrophage cells

At 48 hrs PI, we observed that only a subset of RAW264.7 cells was infected in the form of clusters by CHIKV (less than $5 \%$ of the total population) compared to CLTT (100\% infection). We found that infected RAW cells produced ISG15 but were not stained for phospho IRF3 at $24 \mathrm{~h}$ PI although at a level much lower than CLTT astrocytes. Simultaneous expression of dsRNA (J2 antibody), CHIKV structural proteins (E2, E1, Capsid using FDO human antiserum and mouse anti-E1) and non-structural protein Nsp1 (antiserum) following CHIKV infection of RAW 264.7 cells was also observed (Figures 1 and 2). We used CLTT astrocyte cell line as a positive control of CHIKV infection as shown previously [18]. The release of CHIKV particles from infected cells was confirmed by RTqPCR and plaque assay. By RT-qPCR, CHIKV RNA was detected from $8 \mathrm{~h}$ PI in RAW cells and at a level at least 1000 fold lower when compared to CLTT (Figure 3). In TCS of infected RAW264.7, a stable level of virus $(\sim 3 \times$ $10^{3} \mathrm{pfu} / \mathrm{ml}$ ) was measured at 8,24 and $48 \mathrm{hrs}$ PI compared 


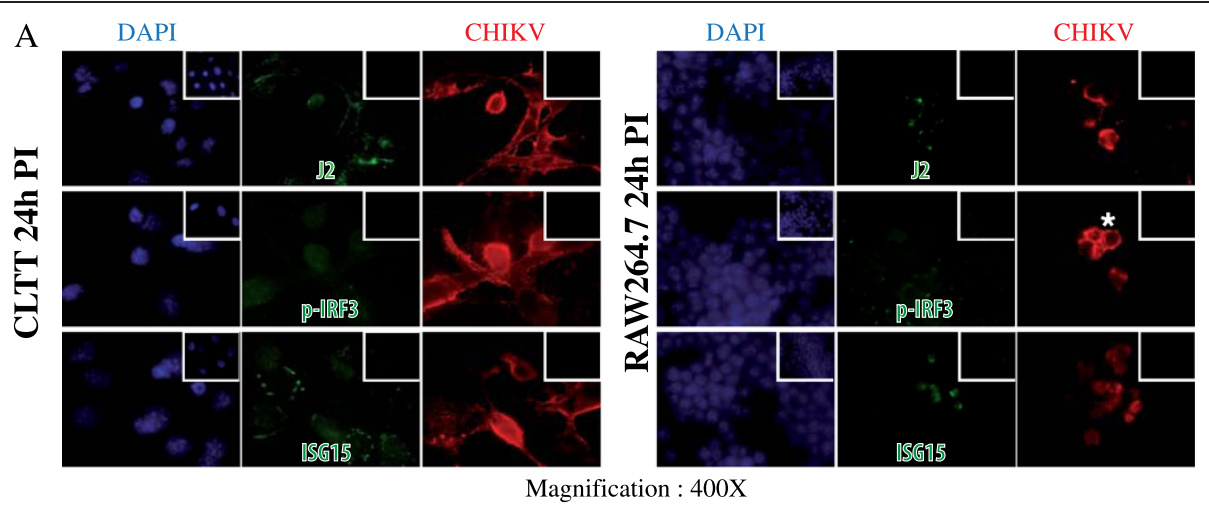

B

CLTT DAPI CHIKV Nsp1

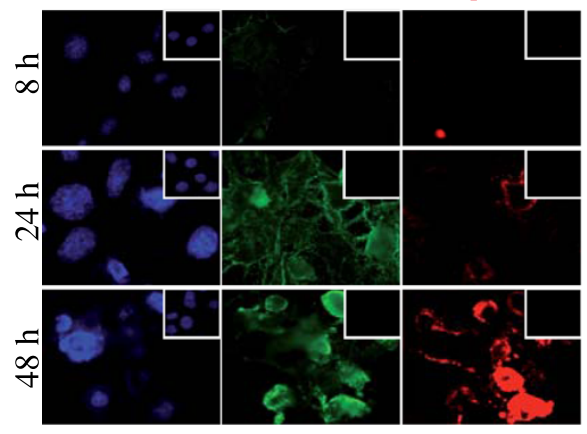

DAPI

RAW264.7

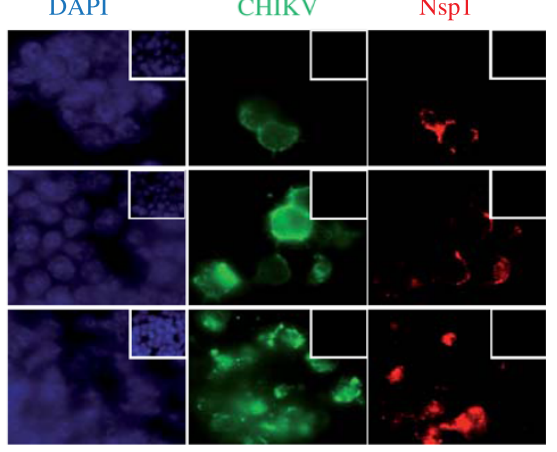

Magnification : 600X

Figure 1 CHIKV infects and replicates in RAW264.7 mouse macrophages. (A) Immunostainings using FDO (human anti-CHIKV polyclonal $\mathrm{Ab}$, red fluorescence) and $\mathrm{J} 2$ (mouse anti-double stranded RNA, green) or ISG-15 or specific rabbit anti-phospho IRF3 at 24 hrs PI. Nuclei were counterstained with DAPI (blue). Only a limited number of total RAW264.7 cells were infected $(<5 \%)$ in form of clusters, as focused on here, compared to CLTT (> 95\% of infected cells). (B) During the time course of infection, both structural and non-structural proteins of CHIKV were produced in infected cells as shown by double staining with FDO (green fluorescence) and rabbit anti cross-reacting SFV/ CHIKV Nsp1 antibody (red fluorescence). Nuclei were stained with DAPI (blue fluorescence). Negative controls are shown as insets. * Cluster of infected cells.

to CLTT (respectively $3.3 \times 10^{7}, 1.3 \times 10^{8}$ and $2.3 \times 10^{7}$ $\mathrm{pfu} / \mathrm{ml}$ at 8,24 and $48 \mathrm{hrs} \mathrm{PI})$. Interestingly, in contrast to CLTT, the level of CHIKV RNA produced in RAW264.7 cells decreased rapidly between 8 and 24 hrs PI to become undetectable at $48 \mathrm{~h}$. Positive strands of CHIKV RNA were detected in both RAW cells and culture supernatants whereas the negative strand was detected only in RAW 264.7 infected cells (Figure 4).

The infection of mouse RAW264.7 macrophage cells by CHIKV does not lead to apoptosis

The majority of CLTT cells at 24 hrs PI were positive for both initiator cleaved caspase-9 and executor cleaved caspase-3 with condensed or fragmented nuclei whereas among the clusters of infected RAW264.7 cells, these markers remained negatives and only a few nuclei were condensed (Figure 2). Moreover, no sign of DNA fragmentation was observed by TUNEL assay for RAW264.7 at $24 \mathrm{hrs}$ PI compare to CLTT (Figure 2C).
RAW264.7 mounts a rather poor innate immune response against CHIKV in contrast to CLTT

RT-qPCR analysis showed no significant changes in IFNa4 and ISG-56 mRNA expression levels for RAW264.7 when compared to CLTT cell line at 24 hrs PI (Figure 5). Since PRRs are critical sensors to initiate the antiviral innate immunity, we also tested TLRs and RIG-I expression in RAW cells prior to and after CHIKV infection. TLR-3, 7, 8 and 9 were not detected (Ct values $>35$ ) and no significant changes were found for RIG-I from 8 to 48 h PI (data not shown).

\section{Robust TNF-alpha expression in CHIKV-infected RAW264.7 cells}

TNF $\alpha$ release was significantly increased at 24 hrs PI (control: $1025 \pm 183 \mathrm{pg} / \mathrm{ml}$ to CHIKV-infected RAW: $3421 \pm$ $766 \mathrm{pg} / \mathrm{ml}, \mathrm{p}=0.02$ ) as measured by ELISA and confirmed by FACS beads array (control: $1021 \pm 266 \mathrm{pg} / \mathrm{ml}$; CHIKV: $3931 \pm 1207 \mathrm{pg} / \mathrm{ml}$ ) (Figure 5B). TNFo expression at the mRNA level was also significantly increased at $24 \mathrm{hrs}$ PI 

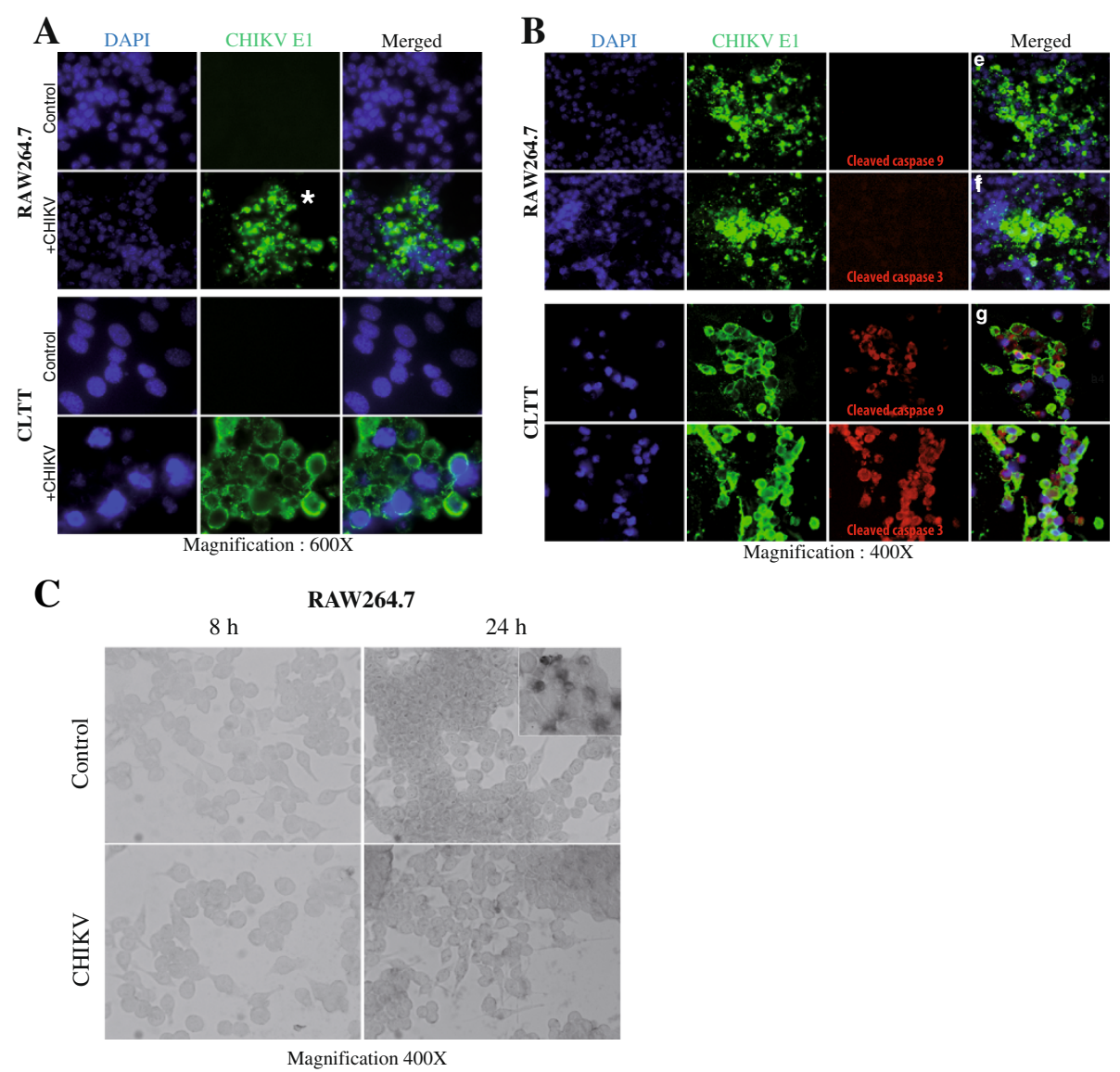

Figure 2 RAW264.7 infected cells does not undergo apoptosis. (A\& B) Immunofluorescence of RAW264.7 and CLTT at 48 hrs PI (mouse monoclonal anti-CHIKV E1, green fluorescence) and apoptosis markers (initiator cleaved caspase-9 or executor cleaved caspase-3, red fluorescence). Nuclei were stained with DAPI (blue fluorescence). (C) No DNA fragmentation (TUNEL assay) was observed in RAW264.7 cells (Inset, positive control of apoptosis) during the time course of infection.

(fold change: $18 \pm 3.2$ over control, $\mathrm{p}=0.034$ ) compared to 8 hrs PI (fold change: $0.6 \pm 0.3$ over control, not significant) (Figure $5 \mathrm{~B}$ ). Low but significantly elevated expression of IL-6 (46.6 pg/ml) and GM-CSF $(395.4 \mathrm{pg} / \mathrm{ml})$ was observed at 24 hrs PI compared to undetectable levels in

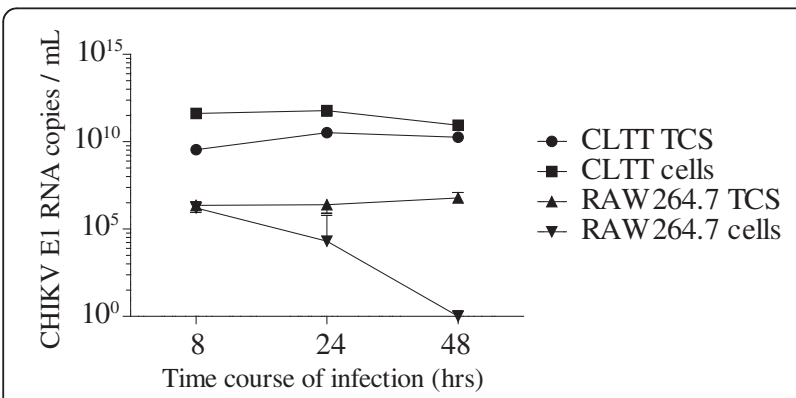

Figure 3 CHIKV replication in RAW (macrophages) and CLTT (astrocyte control). (A) With time, CHIKV RNA raised in RAW264.7 cells and supernatants but remained low compared to CLTT as tested by RTqPCR for E1 $(n=3)$. The graph was plotted after adjusting the background level of the residual virus following the washing steps at T0 (2 hrs PI). mock-infected RAW cells. No expression of IFN- $\gamma$, IL-1 $\alpha$, IL-2, IL-4, IL-5, IL-10 or IL-17 was detected by FACS analysis in RAW TCS prior to and after CHIKV exposure.

\section{Discussion}

There is considerable evidence that several RNA/DNA viruses such as RRV, by Hepatitis C virus (HCV), human immunodeficiency virus (HIV), Measles and cytomegalovirus (CMV) can persist in monocytes macrophages [6,19,20]. In patients suffering from chronic arthritis post RRV- and CHIKV- infection, it is generally accepted that inflammation is associated with productive viral gene expression in synovial macrophages and despite neutralizing antibodies and antiviral interferon/cytokine responses [5,6]. Persistence may be facilitated by down-regulation of pro-inflammatory cytokine responses by virus-antibody complexes binding to Fc receptors, the induction of immunoregulatory interleukin-10 and phagocytosis of apoptotic virus-infected cells in a non-phlogistic manner $[6,21,22]$. Another strategy developed by viruses to persist in infected cells is to render them resistant to apoptosis notably through the up- 


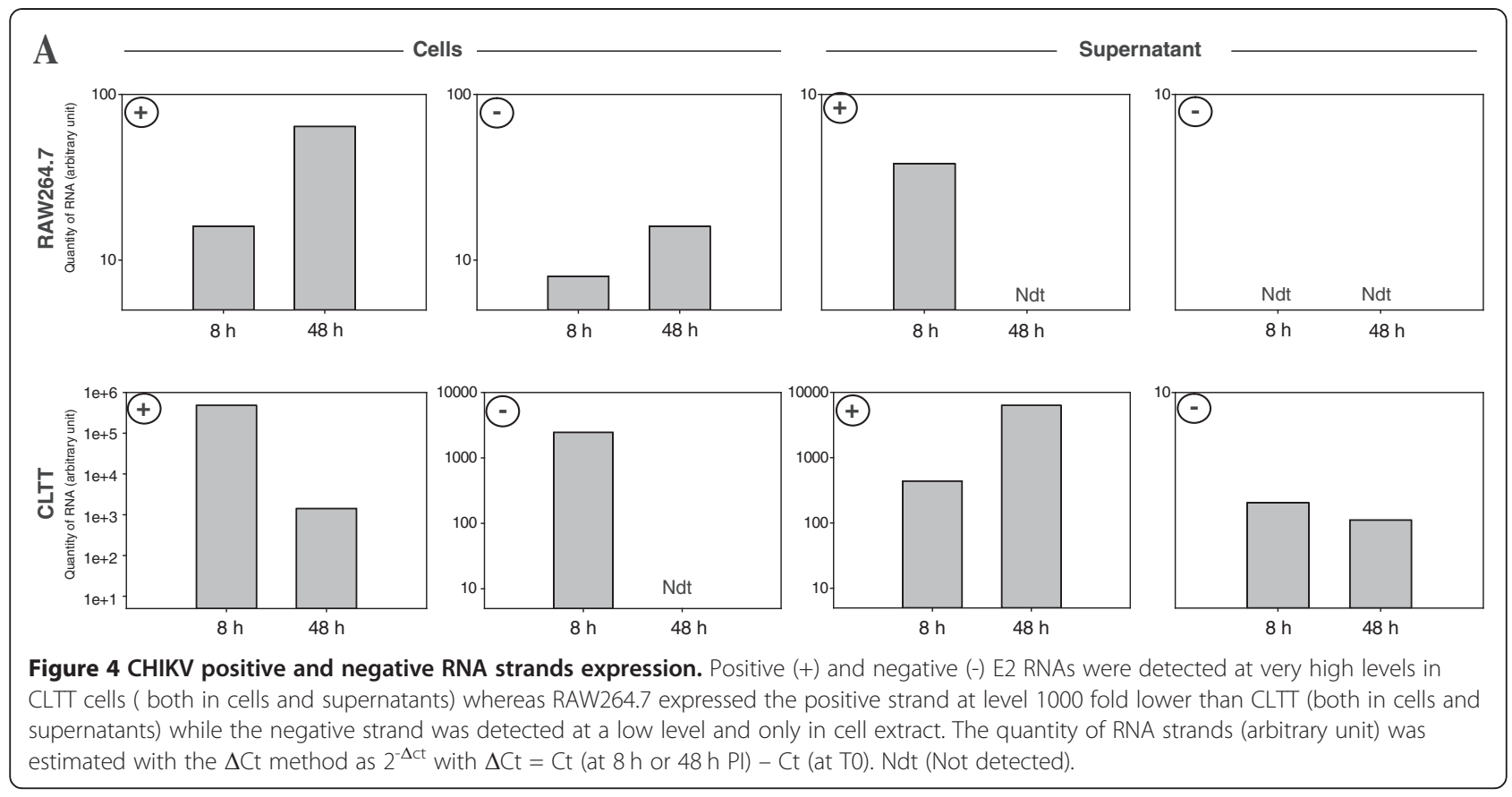

\section{A}

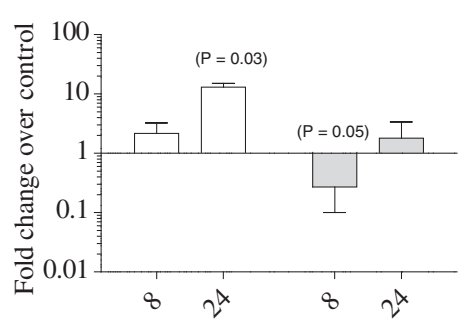

ISG-56

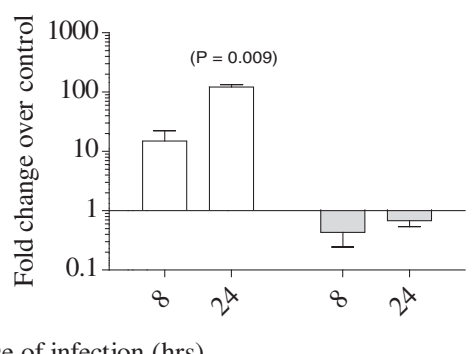

RAW264.7 (ELISA)
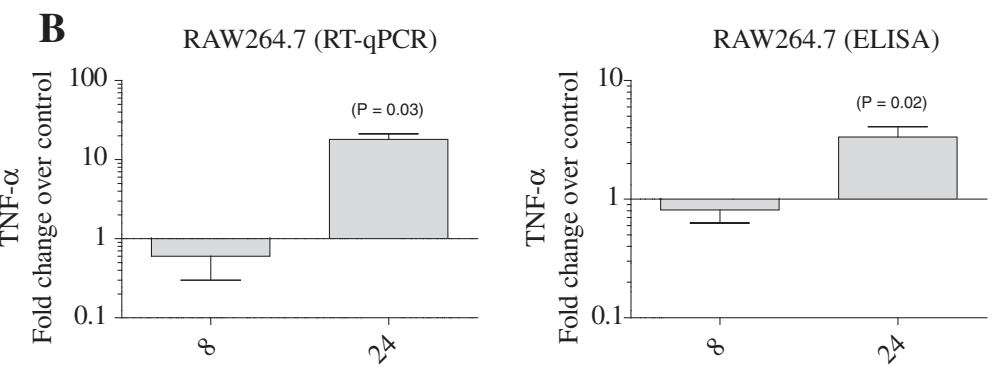

Time course of infection (hrs)

Figure 5 Polarized innate immune response in CHIKV-infected RAW264.7. (A) During the time course of infection, RAW264.7 shows no significant change in IFNa4 mRNA expression by RT-qPCR compared to CLTT. However, a significant increase of ISG-56 at 24 hrs PI was measured for CLTT (fold increase $=121.5 \pm 11.5$ ) compare to RAW264.7 (0.7 \pm 0.1). (B) A significant increase of TNFa for RAW264.7 at $24 \mathrm{hr}$ PI (fold change $=17.9 \pm 3.2$ ) was observed by RT-qPCR and validated by ELISA (fold change $=3.3 \pm 0.3$ ). Fold change over non-infected control is expressed as mean \pm SEM of three independent experiments. 
regulation of the cellular oncogene $\mathrm{Bcl}-2$ and NF- $\mathrm{kB}$ activity $[23,24]$. Our understanding of the possible contribution of these different mechanisms to control CHIKV-persistence and to polarize the innate immune macrophage responses is still in its infancy.

It has already been shown that CHIKV can infect human monocytes/macrophages [12-15] but little is known about the cell response to the infection. Our study shows for the first time that mouse macrophage cell line RAW264.7 can be infected by CHIKV. Interestingly, this occurs only for a subset of cells and spreading to surrounding cells to form clusters of infected cells.

In opposite to previous studies which only shown the capacity of CHIKV to infect macrophages (both cell lines and primary cultures) $[15,21]$, we demonstrate here that RAW264.7 macrophage cells were able to produce also competent CHIKV particles (PFU) during the early phase of infection and this was confirmed by the capacity of the virus to replicate its genome evidenced by the detection of the negative strand RNA. Remarkably, the level of infectious particles produced by RAW cells was much lower when compared to that of CLTT astrocyte cell line.

Type I IFN dependent innate immune response plays an effective role against alphavirus infection [25]. Type I IFN also induces expression of ISGs with antiviral, antiproliferative and immunomodulatory functions. No significant changes of IFN $\alpha 4$ and ISG56 expression in RAW macrophage cells were observed in contrast to robust type I IFN and ISG56 levels in CLTT astrocyte cell line at the same MOI and time PI. Although a low level of ISG15 was evidenced in RAW264.7 infected cells, which could also be induced by IFN-independent pathways [26], only weak levels of phospho-IRF3 translocating to the nucleus was detected. This observation is to be correlated with the low levels of RIG-I in RAW264.7 macrophage cells (even after CHIKV infection) while TLR-3, 7, 8 and 9 were not expressed. Hence, the absence of IFN $\alpha$ and ISG response in infected-RAW264.7 could be due to the lack of PRRs to sense virus RNA and proteins. Many alphaviruses are known to interfere with the IFNAR/Jak/STAT pathway as illustrated in CHIKV-infected Vero cells [27] and this remains to be tested in macrophage cells.

The extrinsic signalling apoptotic pathway involves death receptors that are members of TNF $\alpha$ receptor gene family. Interestingly, we have found robust levels of TNF $\alpha$ mRNA in RAW264.7 cells but not in CLTT astrocytes. This finding was confirmed when looking at the expression of TNF $\alpha$ protein by ELISA and FACS bead assays of TCS. TNFa signalling, in turn, may control apoptosis but this hypothesis was not validated in our RAW264.7 cell model given that cleaved caspase-3 was not detected in RAW264.7 cells. Cleaved caspase-9 (marker of the intrinsic pathway of apoptosis) was also not detected. This finding is in line with the observation that persistent HIV-1 infection of macrophages is linked to increased levels of TNF $\alpha$ controlled by NFKB activation and decreased susceptibility to apoptosis $[23,28]$. Of note, a recent study illustrated the capacity of adjuvant doses of LPS to assist RRV persistence in RAW264.7 cells and this may also involve TLR4/CD14/NFkB signalling to control for apoptosis [29]. Experiments to test whether these paradigms can explain CHIKV persistence in macrophages are now highly warranted at least in vitro.

Understanding the intimate mechanisms of CHIKVpersistence is a prerequisite to devise new and original therapies aiming to control for chronic pathologies experienced by patients even 5-6 years post-infection [30].

\section{Abbreviations \\ (IFs): Immunofluorescence staining; (PI): Post infection; (CHIKV): Chikungunya virus; (IFN): Interferon; (PRR): Pattern recognition receptor; (TLR): Toll-like receptor; (RIG-I): Retinoic acid inducible gene-I; (IFNa4): Interferon alpha 4; (ISG): Interferon stimulated gene; (TNFa): Tumor necrosis factor alpha; (PBS): Phosphate buffer saline; (BSA): Bovine serum albumin; \\ (FACS): Fluorescence analysis cell sorting; (TCS): Tissue culture supernatants.}

\section{Competing interests}

The authors have no competing interests.

\section{Authors' contributions}

Conceived and designed the experiments: KS, HJJ, GP, CG Performed the Experiments: KS; CG, CDKL Analyzed the data: KS, HJJ, CG, GP; Contributed reagents/materials/analysis tools: GP, MCJB, AM; Wrote the paper: KS, HJJ, GP. All authors have read and approved this manuscript.

\section{Acknowledgements}

The authors thank G. Lee Pat Yuen, P. Krejbich-Trotot and V. Thon-Hon for help and Advices. This work is supported by a Ph.D. student fellowship to KS by the Regional Council (Reunion Island). Lab funding has been granted by CPER/FEDER to GRII and other European funding from FP7/ICRES (Integrated Chikungunya Research) project. We thank Dr M. Mallat (INSERM U495, Hôpital Salpétrière, Paris) for kindly providing the CLTT cell line. PG is a fellow of INSERM U945 (Pr B. Autran).

\section{Author details}

${ }^{1}$ GRI/IRG (EA4517), Immunopathology and infectious diseases research grouping, University of La Reunion, CHU and CYROI research centres, St-Denis, La Reunion, France. ${ }^{2}$ Microbiology/Nirology laboratory, CHU Félix-Guyon, Saint-Denis, La Reunion F-97400, France. ${ }^{3}$ Institute of Technology, University of Tartu, Tartu, Estonia. ${ }^{4} G R I$ - (EA4517) Université de la Réunion, Recherche - RDC, CHU Félix-Guyon, Bellepierre, Saint-Denis cedex, lle de la Réunion 97405, France (DOM).

Received: 27 December 2011 Accepted: 12 December 2012 Published: 19 December 2012

\section{References}

1. Mason PJ, Haddow AJ: An epidemic of virus disease in Southern Province, Tanganyika Territory, in 1952-53; an additional note on Chikungunya virus isolations and serum antibodies. Trans $R$ Soc Trop Med Hyg 1957, 51:238-240.

2. Calisher CH, Shope RE, Brandt W, Casals J, Karabatsos N, Murphy FA, Tesh RB, Wiebe ME: Proposed antigenic classification of registered arboviruses I. Togaviridae, Alphavirus. Intervirology 1980, 14:229-232.

3. Tesh RB: Arthritides caused by mosquito-borne viruses. Annu Rev Med 1982, 33:31-40.

4. Mathiot CC, Grimaud G, Garry P, Bouquety JC, Mada A, Daguisy AM, Georges AJ: An outbreak of human Semliki Forest virus infections in Central African Republic. Am J Trop Med Hyg 1990, 42:386-393. 
5. Jaffar-Bandjee MC, Das T, Hoarau JJ, Krejbich Trotot P, Denizot M, Ribera A, Roques P, Gasque P: Chikungunya virus takes centre stage in virally induced arthritis: possible cellular and molecular mechanisms to pathogenesis. Microbes and infection / Institut Pasteur 2009, 11:1206-1218.

6. Suhrbier A, La Linn M: Clinical and pathologic aspects of arthritis due to Ross River virus and other alphaviruses. Curr Opin Rheumatol 2004, 16:374-379

7. Bowie AG, Unterholzner L: Viral evasion and subversion of pattern-recognition receptor signalling. Nat Rev Immunol 2008, 8:911-922.

8. Yoneyama M, Fujita T: RNA recognition and signal transduction by RIG-I-like receptors. Immunol Rev 2009, 227:54-65.

9. Griffin DE, Hardwick JM: Regulators of apoptosis on the road to persistent alphavirus infection. Annu Rev Microbiol 1997, 51:565-592.

10. Cohen JJ: Programmed cell death in the immune system. Adv Immunol 1991, 50:55-85.

11. Rai NK, Tripathi K, Sharma D, Shukla VK: Apoptosis: a basic physiologic process in wound healing. Int J Low Extrem Wounds 2005, 4:138-144.

12. Hoarau JJ, Jaffar Bandjee MC, Krejbich Trotot P, Das T, Li-Pat-Yuen G, Dassa B, Denizot M, Guichard E, Ribera A, Henni T, et al: Persistent chronic inflammation and infection by Chikungunya arthritogenic alphavirus in spite of a robust host immune response. J Immunol 2010, 184:5914-5927.

13. Labadie K, Larcher T, Joubert C, Mannioui A, Delache B, Brochard P, Guigand L, Dubreil L, Lebon P, Verrier B, et al: Chikungunya disease in nonhuman primates involves long-term viral persistence in macrophages. J Clin Invest 2010, 120:894-906.

14. Her Z, Malleret B, Chan M, Ong EK, Wong SC, Kwek DJ, Tolou H, Lin RT, Tambyah PA, Renia L, Ng LF: Active infection of human blood monocytes by Chikungunya virus triggers an innate immune response. J Immunol 2010, 184:5903-5913.

15. Sourisseau M, Schilte C, Casartelli N, Trouillet C, Guivel-Benhassine F, Rudnicka D, Sol-Foulon N, Le Roux K, Prevost MC, Fsihi H, et al: Characterization of reemerging chikungunya virus. PLOS Pathog 2007, 3:e89.

16. Gardner J, Anraku I, Le TT, Larcher T, Major L, Roques P, Schroder WA, Higgs S, Suhrbier A: Chikungunya virus arthritis in adult wild-type mice. J Virol 2010, 84:8021-8032.

17. Pastorino B, Bessaud M, Grandadam M, Murri S, Tolou HJ, Peyrefitte CN: Development of a TaqMan RT-PCR assay without RNA extraction step for the detection and quantification of African Chikungunya viruses. J Virol Methods 2005, 124:65-71.

18. Das T, Jaffar-Bandjee MC, Hoarau JJ, Krejbich Trotot P, Denizot M, Lee-Pat-Yuen G, Sahoo R, Guiraud P, Ramful D, Robin S, et al: Chikungunya fever: CNS infection and pathologies of a re-emerging arbovirus. Prog Neurobiol 2009,

19. Griffin DE: Measles virus-induced suppression of immune responses. Immunol Rev 2010, 236:176-189.

20. Le Douce V, Herbein G, Rohr O, Schwartz C: Molecular mechanisms of HIV-1 persistence in the monocyte-macrophage lineage. Retrovirology 2010, 7:32.

21. Krejbich-Trotot P, Denizot M, Hoarau JJ, Jaffar-Bandjee MC, Das T, Gasque P: Chikungunya virus mobilizes the apoptotic machinery to invade host cell defenses. The FASEB J 2011, 25:314-325

22. Savill J, Dransfield I, Gregory C, Haslett C: A blast from the past: clearance of apoptotic cells regulates immune responses. Nat Rev Immunol 2002, 2:965-975.

23. McElhinny JA, MacMorran WS, Bren GD, Ten RM, Israel A, Paya CV: Regulation of I kappa B alpha and p105 in monocytes and macrophages persistently infected with human immunodeficiency virus. J Virol 1995, 69:1500-1509.

24. Levine B, Huang Q, Isaacs JT, Reed JC, Griffin DE, Hardwick JM: Conversion of lytic to persistent alphavirus infection by the bcl-2 cellular oncogene. Nature 1993, 361:739-742.

25. Ryman KD, Klimstra WB, Nguyen KB, Biron CA, Johnston RE: Alpha/beta interferon protects adult mice from fatal Sindbis virus infection and is an important determinant of cell and tissue tropism. J Virol 2000, 74:3366-3378

26. Chairatvit $K$, Wongnoppavich $A$, Choonate S: Up-regulation of interferonstimulated gene 15 and its conjugates by tumor necrosis factor-alpha via type I interferon-dependent and -independent pathways. Mol Cell Biochem 2012, 368:195-201.
27. Fros JJ, Liu WJ, Prow NA, Geertsema C, Ligtenberg M, Vanlandingham DL, Schnettler E, Vlak JM, Suhrbier A, Khromykh AA, Pijlman GP: Chikungunya virus nonstructural protein 2 inhibits type $I / I$ interferonstimulated JAK-STAT signaling. J Virol 2010, 84:10877-10887.

28. Van Antwerp DJ, Martin SJ, Kafri T, Green DR, Verma IM: Suppression of TNF-alpha-induced apoptosis by NF-kappaB. Science 1996, 274:787-789.

29. Lidbury BA, Rulli NE, Musso CM, Cossetto SB, Zaid A, Suhrbier A, Rothenfluh HS, Rolph MS, Mahalingam S: Identification and characterization of a ross river virus variant that grows persistently in macrophages, shows altered disease kinetics in a mouse model, and exhibits resistance to type I interferon. J Virol 2011, 85:5651-5663.

30. Jaffar-Bandjee MC, Ramful D, Gauzere BA, Hoarau JJ, Krejbich-Trotot P, Robin S, Ribera A, Selambarom J, Gasque P: Emergence and clinical insights into the pathology of Chikungunya virus infection. Expert Rev Anti Infect Ther 2010, 8:987-996.

doi:10.1186/1743-422X-9-313

Cite this article as: Kumar et al:: Mouse macrophage innate immune response to chikungunya virus infection. Virology Journal 2012 9:313.

\section{Submit your next manuscript to BioMed Central and take full advantage of:}

- Convenient online submission

- Thorough peer review

- No space constraints or color figure charges

- Immediate publication on acceptance

- Inclusion in PubMed, CAS, Scopus and Google Scholar

- Research which is freely available for redistribution

Submit your manuscript at www.biomedcentral.com/submit
C) Biomed Central 